\title{
Resistance exercise improves short-term memory through inactivation of NF-KB pathway in mice with Parkinson disease
}

\author{
Sang-Hoon Kim ${ }^{1,2}$, Young Jun $\mathrm{Ko}^{3}$, Seung-Soo Baek ${ }^{1, *}$ \\ 'Department of Sport \& Health Sciences, College of Art \& Culture, Sangmyung University, Seoul, Korea \\ ${ }^{2}$ Department of Physiology, College of Medicine, Kyung Hee University, Seoul, Korea \\ ${ }^{3}$ Major in Sport Service Practice, College of Welfare Convergence, Kangnam University, Youngin, Korea
}

Dysfunctions of Parkinson disease (PD) are classified into motor dysfunction, autonomic nervous system dysfunction, and nonmotor dysfunction, and clinical symptoms such as muscle stiffness, tremors, speech disorders, balance disorders, and slow movements appear. Resistance exercise is a main compartment of exercise programs for $\mathrm{PD}$ patient. The effect of resistant exercise on short-term memory in $\mathrm{PD}$ mice was studied in relation to the activation of nuclear factor (NF)- $\mathrm{KB}$ pathway. PD was induced by subcutaneous injection of 1-methyl-4phenyl-1,2,3,6-tetrahydropyridine. For resistance exercise, mice performed ladder climbing 5 days per week for 5 weeks. Step-down avoidance test for short-term memory, enzyme-linked immunoassay for tumor necrosis factor (TNF)- $\alpha$, interleukin (IL)- 6 , and IL-1 $\beta$, Western bot for NF-kB, NF-kB inhibitor (IkB)- $\alpha$, B-cell lymphoma 2 (Bcl-2)-associated $X$ protein (Bax), and $B c l-2$, and immunohistochemistry for cleaved caspase- 3 were done. Latency time was shortened, TNF- $\alpha$, IL-6, and
IL-1 $\beta$ concentration was increased, NF- $\mathrm{kB}$ expression and IKB- $\alpha$ phosphorylation were increased, cleaved caspase-3 and Bax expression was enhanced, and $\mathrm{Bcl}-2$ expression was suppressed by PD induction. Latency time was lengthened, TNF- $\alpha$, IL-6, and IL- $1 \beta$ concentration was decreased, NF-KB expression and IкB- $\alpha$ phosphorylation were suppressed, cleaved caspase- 3 and Bax expression was decreased, and $\mathrm{Bcl}-2$ expression was increased in PD mice by resistance exercise or levodopa treatment. Resistance exercise improved short-term memory by inhibiting secretion of proinflammatory cytokines and apoptosis through inactivation of NF-kB. These effects of resistance exercise were similar to levodopa treatment.

Keywords: Parkinson disease, Resistance exercise, Nuclear factor-кB, Apoptosis

\section{INTRODUCTION}

Dysfunctions of Parkinson disease (PD) are classified into motor dysfunction, autonomic nervous system dysfunction, and nonmotor dysfunction, and clinical symptoms such as muscle stiffness, tremors, speech disorders, balance disorders, and slow movements appear. (Jankovic, 2008). Increased oxidative stress, mitochondrial dysfunction, and excitatory toxicity are suggested as causative factors for PD (Blandini, 2010), but the exact cause is still unknown. Treatment drugs for PD include levodopa, which stimulates dopamine receptors, as well as anticholinergic drugs that reduce tremors, and sellegiline, a drug that inhibits monoamine oxidant B (Dezsi and Vecsei, 2017). Mice with PD showed poor motor balance and coordination with nigrostriatal dopaminergic neuronal loss (Sung et al., 2012).

Step-down avoidance test is behavior test to determine shortterm memory (Ji et al., 2020). Treadmill running improved shortterm memory by inhibiting apoptosis through phosphorylation of extracellular signal-regulated protein kinase/protein kinase B/cyclic adenosine monophosphate-responsive element binding protein/brain-derived neurotrophic factor pathway in the hippocampus of ischemia gerbils (Lee et al., 2020).
${ }^{*}$ Corresponding author: Seung-Soo Baek (iD https://orcid.org/0000-0002-1340-2098 Department of Sport \& Health Care, College of Art \& Culture, Sangmyung University, 20 Hongjimun 2-gil, Jongno-gu, Seoul 03016, Korea Email: ssoop@smu.ac.kr

Received: February 10, 2021 / Accepted: March 15, 2021
This is an Open Access article distributed under the terms of the Creative Commons Attribution Non-Commercial License (https://creativecommons.org/licenses/by-nc/4.0/) which permits unrestricted non-commercial use, distribution, and reproduction in any medium, provided the original work is properly cited. 
Inflammatory cells produced tumor necrosis factor (TNF)- $\alpha$, interleukin (IL)-1 $\beta$, and IL-6, and the secretion of these proinflammatory cytokines was enhanced by nuclear factor (NF)- $\mathrm{kB}$ activation (Wang et al., 2019). Overproduction of TNF- $\alpha$, IL-1 $\beta$, and IL-6 exacerbated the progress of acute liver injury (Ko et al., 2020), and thus inhibition of proinflammatory cytokines is presented as a guideline for the treatment of acute liver injury.

Secretion of proinflammatory cytokines is enhanced by stimulating NF- $\mathrm{kB}$, and NF- $\mathrm{kB}$ activation plays a fundamental role in causing neuroinflammatory apoptosis (Guan et al., 2019; Wu et al., 2019). Inhibition on NF-kB suppressed inducible nitric oxide, cyclooxygenase 2 , nitric oxide, and prostaglandin 2 (inflammatory mediators) expression and TNF- $\alpha$, IL- 6 , and IL-1 $\beta$ (proinflammatory cytokines) production (Subedi et al., 2019). $\mathrm{CCl}_{4}$ injection induced liver damage by NF-kB activation through $\mathrm{IkB} \alpha$ phosphorylation (Ko et al., 2020). Voluntary wheel running effectively reduced the NF- $\kappa \mathrm{B}$ pathway activated by brain inflammation (Ko and $\mathrm{Ko}, 2020$ ).

Apoptosis is one of the types of cell death that eliminates dying cells, and apoptosis regulates normal development and tissue homeostasis. However, excessively promoted apoptosis causes many neuropsychiatric diseases (Lee et al., 2020; Song et al., 2018). Caspase- 3 acts as an executor of apoptosis among caspases, and an overexpressing B-cell lymphoma $2(\mathrm{Bcl}-2)$-associated $\mathrm{X}$ protein (Bax) indicates apoptosis (Lee et al., 2020; Song et al., 2018). When Bax is in exceeded, apoptosis resumes as $\mathrm{Bcl}-2$ is consumed in the complexes with Bax (Dlugosz et al., 2006).

Exercise modulates signaling pathways involved in neuroplasticity in the hippocampus (Staples et al., 2015). High-intensity resistance exercise training improved motor function, physical capacity, and fatigue perception (Kelly et al., 2014). Low-volume resistance training improved physical function of PD older people, suggesting that resistance exercise is a main compartment of exercise programs for PD patient (Leal et al., 2019). In the current study, the effect of resistant exercise on short-term memory in PD mice was studied in relation to the activation of NF- $\mathrm{kB}$ pathway.

\section{MATERIALS AND METHODS}

\section{Experimental animals}

For this experiment, male ICR mice weighing $30 \pm 2 \mathrm{~g}$ (10 weeks old) were used. This experimental procedure was approved by the Kyung Hee University Animal Ethics Committee (KHUSASP [SE]-18-151). Mice were divided into control group, PD group, PD and resistance exercise group, and PD and levodopa-treated group.

\section{Induction of PD}

PD was induced as written below (Sung et al., 2012). The experimental animals were intraperitoneally injected with probenecid diluted in dimethyl sulfoxide $(250 \mathrm{mg} / \mathrm{kg}$, Sigma-Aldrich Chemical Co., St. Louis, MO, USA). After 30 min of injection of probenecid, $100 \mu \mathrm{L}$ 1-methyl-4-phenyl-1,2,3,6-tetrahydropyridine (20 mg/kg MPTP; Sigma-Aldrich Chemical Co.) diluted in $0.9 \%$ saline was subcutaneously injected. All groups except control group were injected with MPTP 10 times over 5 weeks.

\section{Resistance exercise and drug treatment}

Resistance exercise was performed as written below (Kim, 2019). From 7 days after MPTP injection, mice in the exercise group were made to climb the ladder 5 days per week for 5 weeks. Weights corresponding to $30 \%$ of body weight in the first week, $40 \%$ of body weight in 2-3 weeks, and $50 \%$ of body weight in 4-5 weeks were attached to the tail. Mice in the levodopa-treated group received $25 \mathrm{mg} / \mathrm{kg}$ levodopa $(100 \mu \mathrm{L})$ orally, 5 days per week for 5 weeks.

\section{Step-down avoidance test}

Step-down avoidance test was done 36 days after starting of experiment as written below (Ji et al., 2020). Mice were stabilized on a platform ( $7 \mathrm{~cm}$ wide, $25 \mathrm{~cm}$ long, $2.5 \mathrm{~cm}$ high) for $1 \mathrm{~min}$. When the mouse descended into a space composed of iron rods (42 cm in width and $25 \mathrm{~cm}$ in length), $0.5-\mathrm{mA}$ electric shock was applied to the foot for $2 \mathrm{sec}$. After $2 \mathrm{hr}$, the test was repeated and staying time on platform was recorded. Latency time of $180 \mathrm{sec}$ or more was considered as $180 \mathrm{sec}$.

\section{Tissue preparation}

After completion the step-down avoidance test, all experimental animals were anesthetized with Zoletil $50(10 \mathrm{mg} / \mathrm{kg}$, Vibac Laboratories, Carros, France), and sacrificed. Mice were injected with $50 \mathrm{mM}$ phosphate-buffered saline through the heart, and infused with $4 \%$ paraformaldehyde for fixation. After the brains of mice were taken out, $40-\mu \mathrm{m}$-thick coronal sections were made using a frozen microtome (Leica, Nussloch, Germany).

\section{Proinflammatory cytokines}

The enzyme-linked immunoassay for TNF- $\alpha$, IL- 6 , and IL-1 $\beta$ in the hippocampus was done using enzyme immunoassay kit (Abcam, Cambridge, UK) as written below (Ko et al., 2020). 
Table 1. Primary and secondary antibodies in Western blot

\begin{tabular}{|c|c|c|c|c|}
\hline Classification & Items & Source & Titer & Company \\
\hline \multirow[t]{3}{*}{ Primary antibody } & Nuclear factor-кB & Anti-rabbit & $1: 1,000$ & Abcam, Cambridge, UK \\
\hline & NF-кB inhibitor (lкB)- $\alpha$, phosphorylated $l_{\mathbf{K}} B-\alpha$ & Anti-rabbit & $1: 1,000$ & Santa Cruz Biotechnology, Santa Cruz, CA, USA \\
\hline & B-cell lymphoma-2 (Bcl-2)-associated X protein (Bax), Bcl-2, $\beta$-actin & Anti-mouse & $1: 1,000$ & Santa Cruz Biotechnology, Santa Cruz, CA, USA \\
\hline Secondary antibody & Horseradish peroxidase-conjugated lgG & $\begin{array}{l}\text { Mouse } \\
\text { Rabbit }\end{array}$ & $1: 2,000$ & Vector Laboratories, Burlingame, CA, USA \\
\hline
\end{tabular}

\section{Western blotting}

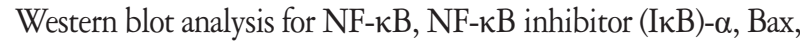
and $\mathrm{Bcl}-2$ in the hippocampus was done as written below (Ko and Ko, 2020). The harvest hippocampal tissues were homogenized on chilled radioimmunoprecipitation assay buffer (Cell Signaling Technology, Inc., Danvers, MA, USA). After centrifugation at 14,000 rpm for $30 \mathrm{~min}$ at $4^{\circ} \mathrm{C}$, the content was determined using a $\mu$-drop reader (Thermo Fisher Scientific, New Jersey, NJ, USA). After transferring the protein to the nitrocellulose membrane, primary antibodies and second antibodies were used as shown in Table 1.

\section{Immunohistochemistry}

Immunohistochemistry for cleaved caspase-3 in the hippocampus was done as written below (Ko et al., 2020). The tissues were treated with rabbit anti-cleaved caspase-3 antibody (1:500; Cell Signaling Technology) overnight, then the tissues were treated with biotinylated rabbit secondary antibody (1:200; Vector Laboratories, Burlingame, CA, USA) for $1 \mathrm{hr}$. The ABC kit (1:100; Vector Laboratories) was used for secondary antibody amplification and the antibody biotin-avidin-peroxidase complex was visualized by $0.03 \%$ diaminobenzidine.

\section{Data analysis}

Data were analyzed by one-way analysis of variance with Duncan post hoc test using IBM SPSS Statistics ver. 25.0 (IBM Co., Armonk, NY, USA). Statistical significance was defined as $P<0.05$.

\section{RESULTS}

\section{Latency time}

Latency time in the step-down avoidance test was shown in Fig. 1. Latency time was shortened by PD induction $(P<0.05)$, whereas resistance exercise or levodopa treatment prolonged latency time in PD mice $(P<0.05)$.

\section{Concentration of TNF- $\alpha$, IL- 6 , and IL-1 $\beta$}

Concentration of TNF- $\alpha$, IL- 6 , and IL-1 $\beta$ was presented in

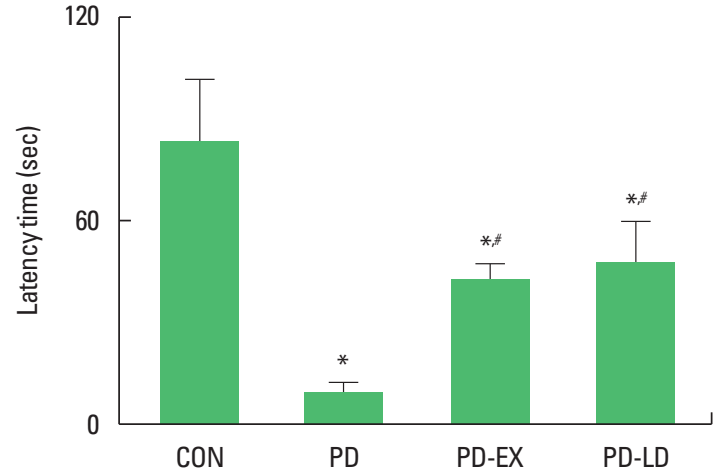

Fig. 1. Short-term memory. CON, control group; PD, Parkinson disease group; PD-EX, Parkinson disease and resistance exercise group; PD-LD, Parkinson disease and levodopa-treated group. ${ }^{*} P<0.05$ compared with the control group. ${ }^{\sharp} P<0.05$ compared with the Parkinson disease group.

Fig. 2. Concentration of TNF- $\alpha$, IL- 6 , and IL-1 $\beta$ was enhanced by PD induction $(P<0.05)$, whereas resistance exercise or levodopa treatment suppressed TNF- $\alpha$, IL- 6 , and IL-1 $\beta$ concentration in PD mice $(P<0.05)$.

\section{NF-кB expression and IкB- $\alpha$ phosphorylation}

NF- $\kappa B$ expression and I $\kappa$ B- $\alpha$ phosphorylation were presented

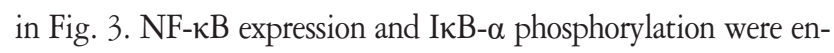
hanced by $\mathrm{PD}$ induction $(P<0.05)$, whereas resistance exercise or levodopa treatment suppressed NF- $\mathrm{BB}$ expression and IкB- $\alpha$ phosphorylation in PD mice $(P<0.05)$.

\section{Cleaved caspase-3, Bax, and Bcl-2 expression}

Expression of cleaved caspase-3, Bax, and Bcl-2 was presented in Fig. 4. Cleaved caspase-3 expression was enhanced by PD induction $(P<0.05)$, whereas resistance exercise or levodopa treatment reduced cleaved caspase- 3 expression in PD rats. Bax expression was enhanced and $\mathrm{Bcl}-2$ expression was suppressed by PD induction $(P<0.05)$, causing in increment of $\mathrm{Bax}$ to $\mathrm{Bcl}-2$ ratio. On the contrary, resistance exercise or levodopa treatment suppressed Bax expression and enhanced Bcl-2 expression in PD mice $(P<$ $0.05)$, causing in decrement of $\mathrm{Bax}$ to $\mathrm{Bcl}-2$ ratio. 

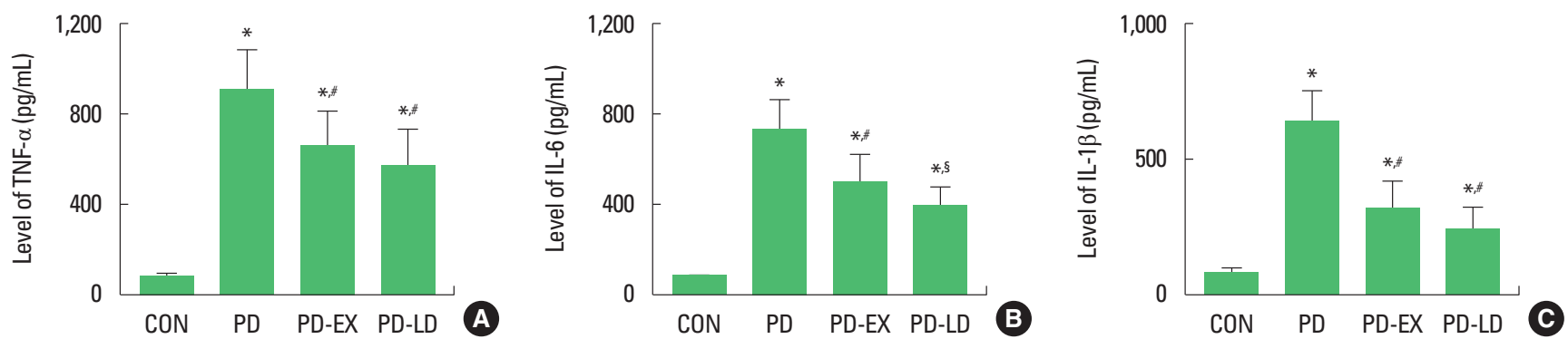

Fig. 2. Proinflammatory cytokines in the hippocampus. (A) Concentration of tumor necrosis factor- $\alpha$ (TNF- $\alpha$ ) in the hippocampus. (B) Concentration of interleukin (IL)-6 in the hippocampus. (C) Concentration of IL-1 $\beta$ in the hippocampus. CON, control group; PD, Parkinson disease group; PD-EX, Parkinson disease and resistance exercise group; $\mathrm{PD}-\mathrm{LD}$, Parkinson disease and levodopa-treated group. ${ }^{*} P<0.05$ compared with the control group. ${ }^{\#} P<0.05$ compared with the Parkinson disease group. ${ }^{\S} P<0.05$ compared with the Parkinson disease and resistance exercise group.
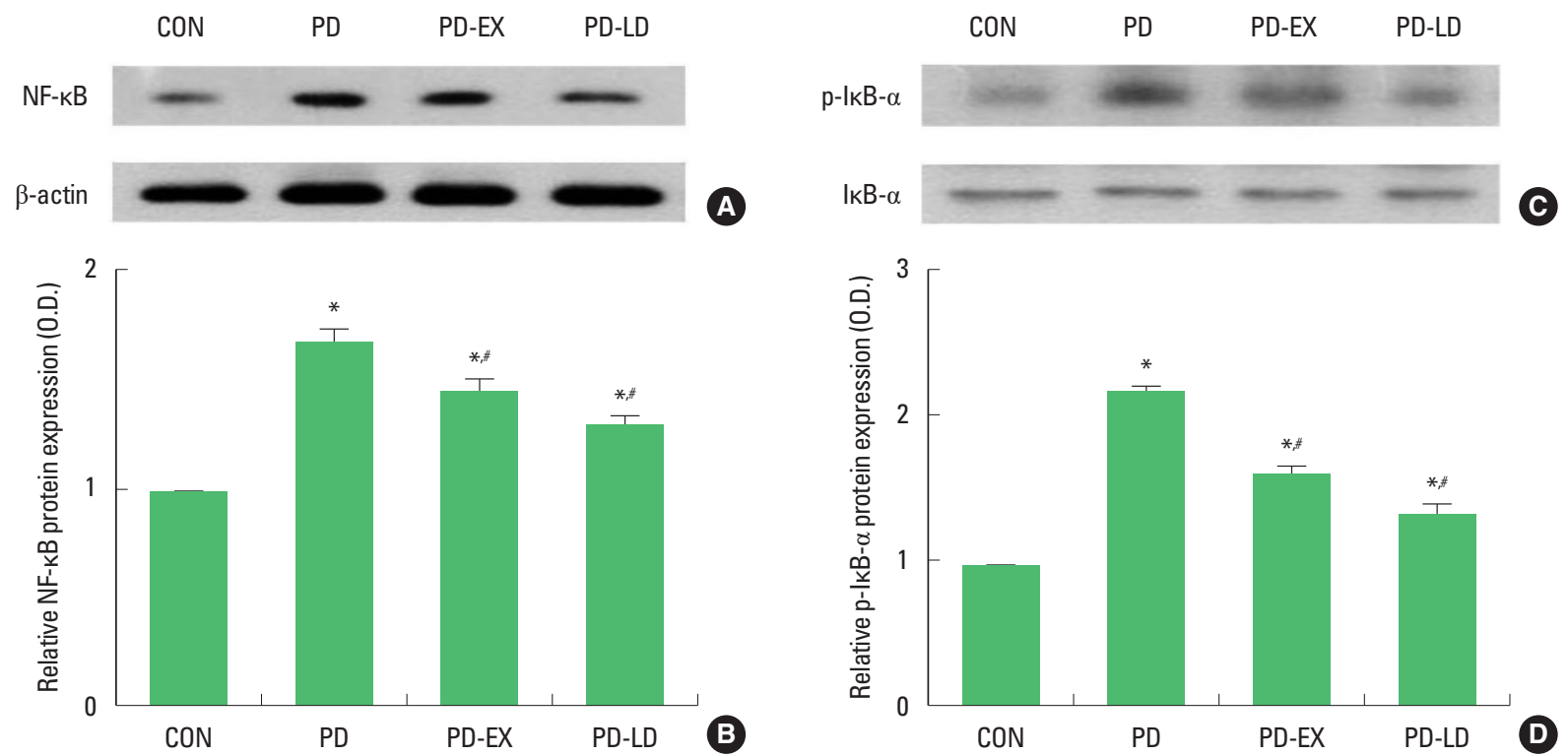

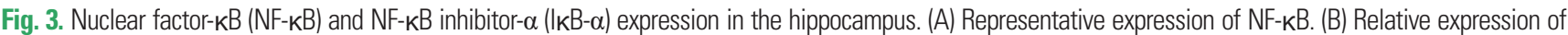
NF-kB. (C) Representative expression of $I_{\kappa B} B-\alpha$. (D) Relative expression of $I_{\kappa} B-\alpha$. CON, control group; PD, Parkinson disease group; PD-EX, Parkinson disease and resistance exercise group; PD-LD, Parkinson disease and levodopa-treated group. ${ }^{*} P<0.05$ compared with the control group. ${ }^{\#} P<0.05$ compared with the Parkinson disease group.

\section{DISCUSSION}

Progressive resistance exercise, which incrementally increases load, was more effective in improving cognitive function than fixed load exercise (David et al., 2015). Wheel running exercise following brain inflammation inhibited apoptotic cell death by suppressing the production of proinflammatory cytokines in the hippocampus, thereby improved spatial learning memory (Ko and Ko, 2020). Latency of the step-down avoidance test was shortened by ischemia insult, showing that short-term memory was impaired by ischemia in gerbils (Lee et al., 2020). Treadmill running lengthened the latency, showing that exercise improved short-term mem- ory in ischemic gerbils (Lee et al., 2020). Latency was shortened in the high-fat diet rats, representing that short-term memory was disturbed in the high-fat diet rats, meanwhile, treadmill running increased latency in the high-fat diet rats, representing that shortterm memory was improved by treadmill running in the high-fat diet rats (Ji et al., 2020). In the current study, PD induction shortened latency time, meanwhile, latency time in PD mice was lengthened by resistance exercise and levodopa treatment, showing that resistance exercise and levodopa improved short-term memory.

Lipopolysaccharide (LPS) injection through brain ventricle increased TNF- $\alpha$ and IL- 6 expression, whereas wheel running exercise suppressed TNF- $\alpha$ and IL- 6 expression in brain inflammation- 

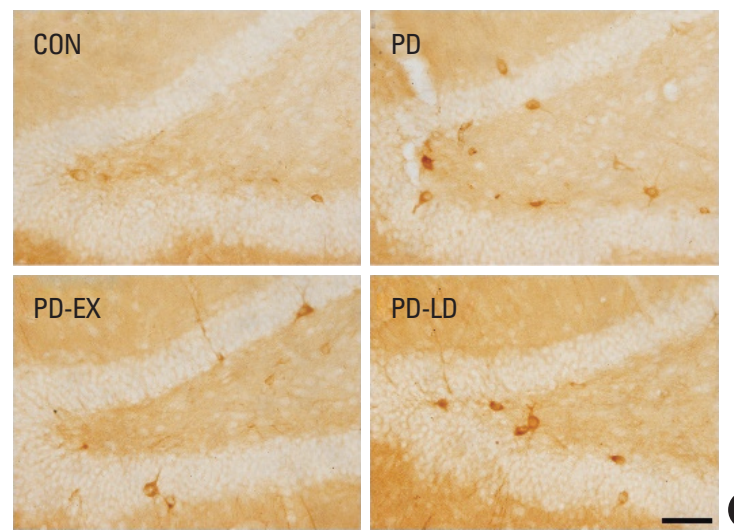

A

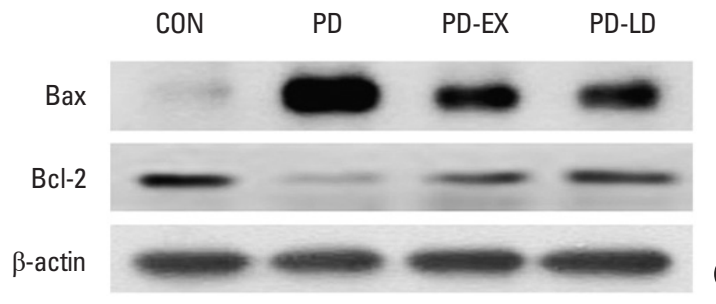

(

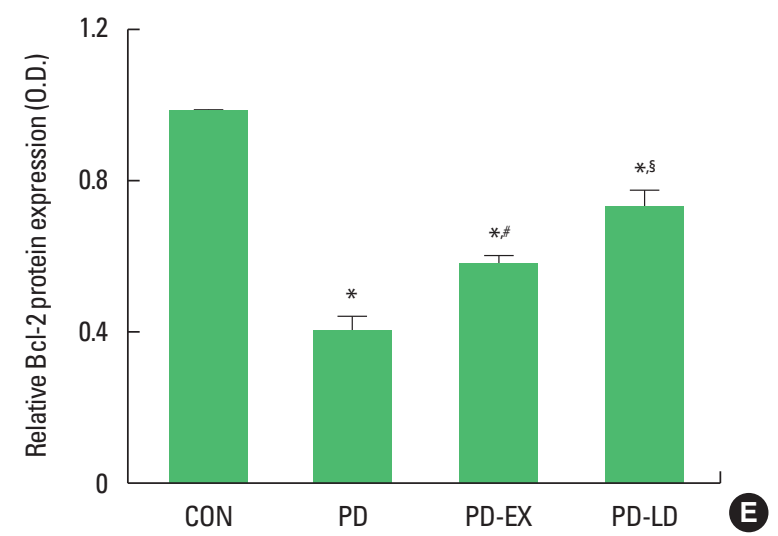

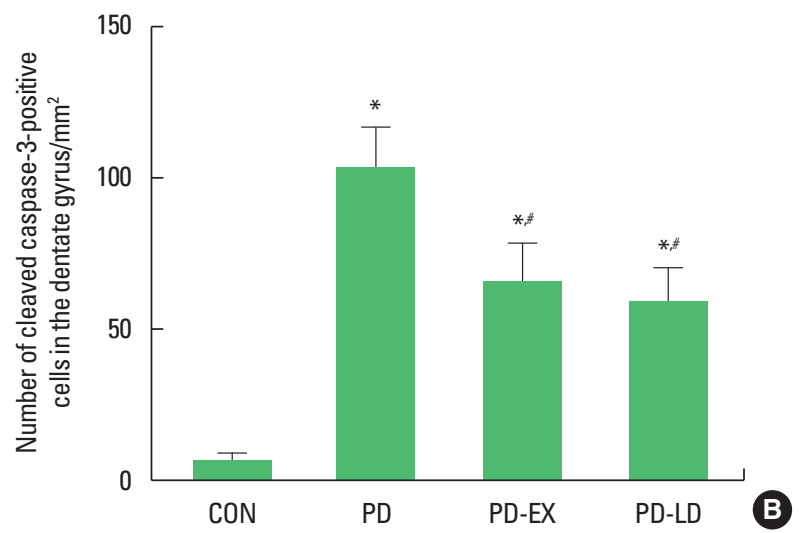
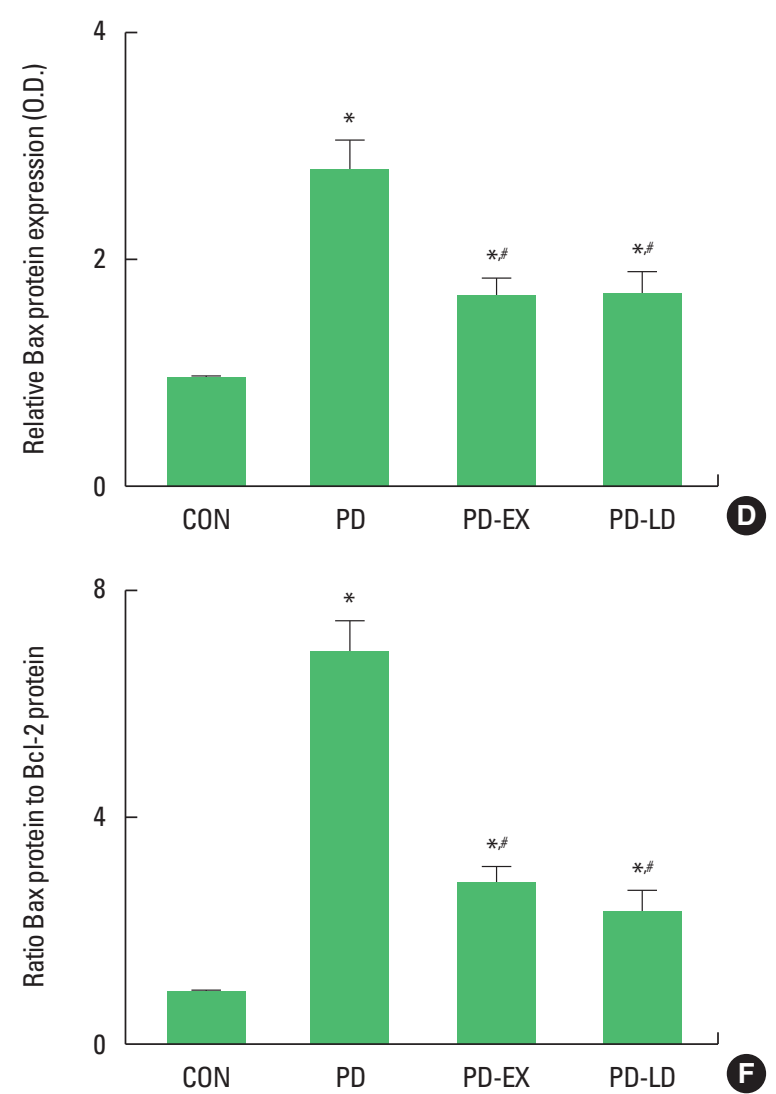

Fig. 4. Cleaved caspase-3, Bcl-2-associated X protein (Bax), B-cell lymphoma-2 (Bcl-2) expression in the hippocampus. (A) Photomicrography of cleaved caspase-3-positive cells. The scale bar represents $200 \mu \mathrm{m}$. (B) Number of cleaved caspase-3-positive cells in the hippocampal dentate gyrus. (C) Representative expression of Bax and Bcl-2. (D) Relative Bax expression. (E) Relative Bcl-2 expression. (F) Relative ratio of Bax to Bcl-2. CON, control group; PD, Parkinson disease group; PD-EX, Parkinson disease and resistance exercise group; PD-LD, Parkinson disease and levodopa-treated group. ${ }^{*} P<0.05$ compared with the control group. ${ }^{\#} P<0.05$ compared with the Parkinson disease group. ${ }^{\S} P<0.05$ compared with the Parkinson disease and resistance exercise group.

induced rats (Ko and Ko, 2020). In the current study, PD induction increased concentration of TNF- $\alpha$, IL- 6 , and IL- $1 \beta$, meanwhile, TNF- $\alpha$, IL- 6 , and IL- $1 \beta$ concentration in PD mice was decreased by resistance exercise and levodopa treatment, showing that resistance exercise and levodopa alleviated proinflammatory cytokine production.

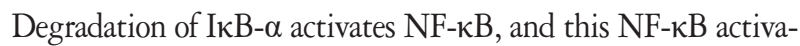
tion increased secretion of proinflammatory cytokines (Wu et al., 2019). LPS-induced brain inflammation increased phosphoryla-

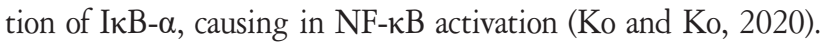


When the expression of NF- $\mathrm{kB}$ was enhanced by the activation of NF- $\kappa B$, TNF- $\alpha$, and IL- 6 expression in the hippocampus was increased (Ko and Ko, 2020). In the current study, PD induction enhanced NF- $\kappa \mathrm{B}$ expression by phosphorylation of I $\mathrm{B}-\alpha$, whereas NF- $\mathrm{KB}$ expression was suppressed by inhibiting IкB- $\alpha$ phosphorylation by resistance exercise and levodopa treatment in PD mice, showing that resistance exercise and levodopa inactivated NF-кB.

Cleaved caspase-3 expression and Bax to Bcl-2 ratio were increased by $\mathrm{CCl}_{4}$ treatment, showing that $\mathrm{CCl}_{4}$ initiated apoptosis (Ko et al., 2020). In social isolation old rats, swimming inhibited Bax expression and enhanced Bcl-2 expression, indicating that apoptosis was supressed (Park et al., 2020). Voluntary wheel running suppressed cleaved caspase-3 expression with Bax expression and enhanced $\mathrm{Bcl}-2$ expression in the hippocampus of the brain inflammation rats (Ko and Ko, 2020). In the current study, PD induction increased cleaved caspase- 3 expression and Bax expression and suppressed Bcl-2 expression, meanwhile, cleaved caspase-3 expression and Bax expression was inhibited and $\mathrm{Bcl}-2$ expression was increased by resistance exercise and levodopa treatment in PD mice, showing that resistance exercise and levodopa inhibited apoptosis.

Current results demonstrated that resistance exercise improved short-term memory by inhibiting proinflammatory cytokine secretion and apoptosis through inactivation of NF- $\mathrm{KB}$. These effects of resistance exercise were similar to levodopa treatment. Resistance training can be suggested as one of the key elements of exercise program patients with PD.

\section{CONFLICT OF INTEREST}

No potential conflict of interest relevant to this article was reported.

\section{ACKNOWLEDGMENTS}

This work was supported by the Ministry of Education of the Republic of Korea and the National Research Foundation of Korea (NRF-2018S1A5A2A01036668).

\section{REFERENCES}

Blandini F. An update on the potential role of excitotoxicity in the pathogenesis of Parkinson's disease. Funct Neurol 2010;25:65-71.

David FJ, Robichaud JA, Leurgans SE, Poon C, Kohrt WM, Goldman JG,
Comella CL, Vaillancourt DE, Corcos DM. Exercise improves cognition in Parkinson's disease: the PRET-PD randomized, clinical trial. Mov Disord 2015;30:1657-1663.

Dezsi L, Vecsei L. Monoamine oxidase B inhibitors in Parkinson's disease. CNS Neurol Disord Drug Targets 2017;16:425-439.

Dlugosz PJ, Billen LP, Annis MG, Zhu W, Zhang Z, Lin J, Leber B, Andrews DW. Bcl-2 changes conformation to inhibit Bax oligomerization. EMBO J 2006;25:2287-2296.

Guan F, Zhou X, Li P, Wang Y, Liu M, Li F, Cui Y, Huang T, Yao M, Zhang Y, Ma J, Ma S. MG53 attenuates lipopolysaccharide-induced neurotoxicity and neuroinflammation via inhibiting TLR4/NF- $\kappa$ B pathway in vitro and in vivo. Prog Neuropsychopharmacol Biol Psychiatry 2019;95:109684.

Jankovic J. Parkinson's disease: clinical features and diagnosis. J Neurol Neurosurg Psychiatry 2008;79:368-376.

Ji ES, Kim YM, Ko YJ, Baek SS. Treadmill exercise in obese maternal rats during pregnancy improves short-term memory through neurogenesis in the hippocampus of rat pups. J Exerc Rehabil 2020;16:392-397.

Kelly NA, Ford MP, Standaert DG, Watts RL, Bickel CS, Moellering DR, Tuggle SC, Williams JY, Lieb L, Windham ST, Bamman MM. Novel, high-intensity exercise prescription improves muscle mass, mitochondrial function, and physical capacity in individuals with Parkinson's disease. J Appl Physiol (1985) 2014;116:582-592.

Kim J. Low-intensity tower climbing resistance exercise reduces experimentally induced atopic dermatitis in mice. J Exer Rehabil 2019;15: 518-525.

Ko IG, Jin JJ, Hwang L, Kim SH, Kim CJ, Han JH, Lee S, Kim HI, Shin HP, Jeon JW. Polydeoxyribonucleotide exerts protective effect against $\mathrm{CCl}_{4}$ induced acute liver injury through inactivation of NF- $\mathrm{B} / \mathrm{MAPK}$ signaling pathway in mice. Int J Mol Sci 2020;21:7894.

Ko YJ, Ko IG. Voluntary wheel running improves spatial learning memory by suppressing inflammation and apoptosis via inactivation of nuclear factor kappa B in brain inflammation rats. Int Neurourol J 2020; 24:96-103.

Leal LC, Abrahin O, Rodrigues RP, da Silva MC, Araújo AP, de Sousa EC, Pimentel CP, Cortinhas-Alves EA. Low-volume resistance training improves the functional capacity of older individuals with Parkinson's disease. Geriatr Gerontol Int 2019;19:635-640.

Lee SS, Kim CJ, Shin MS, Lim BV. Treadmill exercise ameliorates memory impairment through ERK-Akt-CREB-BDNF signaling pathway in cerebral ischemia gerbils. J Exerc Rehabil 2020;16:49-57.

Park SS, Park HS, Kim TW, Lee SJ. Effects of swimming exercise on social isolation-induced memory impairment and apoptosis in old rats. J Exerc Rehabil 2020;16:234-241.

Song SH, Jee YS, Ko IG, Lee SW, Sim YJ, Kim DY, Lee SJ, Cho YS. Tread- 
mill exercise and wheel exercise improve motor function by suppressing apoptotic neuronal cell death in brain inflammation rats. J Exerc Rehabil 2018;14:911-919.

Staples MC, Somkuwar SS, Mandyam CD. Developmental effects of wheel running on hippocampal glutamate receptor expression in young and mature adult rats. Neuroscience 2015;305:248-256.

Subedi L, Lee JH, Yumnam S, Ji E, Kim SY. Anti-inflammatory effect of sulforaphane on LPS-activated microglia potentially through JNK/ AP-1/NF-kB inhibition and Nrf2/HO-1 activation. Cells 2019; 8:194.

Sung YH, Kim SC, Hong HP, Park CY, Shin MS, Kim CJ, Seo JH, Kim DY,
Kim DJ, Cho HJ. Treadmill exercise ameliorates dopaminergic neuronal loss through suppressing microglial activation in Parkinson's disease mice. Life Sci 2012;91:1309-1316.

Wang Y, Feng L, Liu S, Zhou X, Yin T, Liu Z, Yang Z. Transcranial magneto-acoustic stimulation improves neuroplasticity in hippocampus of Parkinson's disease model mice. Neurotherapeutics 2019;16:1210-1224.

Wu X, Liu C, Chen L, Du YF, Hu M, Reed MN, Long Y, Suppiramaniam V, Hong H, Tang SS. Protective effects of tauroursodeoxycholic acid on lipopolysaccharide-induced cognitive impairment and neurotoxicity in mice. Int Immunopharmacol 2019;72:166-175. 